\title{
PENGARUH DESAIN KERJA DAN MANAJEMEN TEKNOLOGI INFORMASI TERHADAP MUTU PELAYANAN GURU SMK NEGERI DI WILAYAH JAKARTA UTARA
}

\author{
Sopiah* $^{*}$
}

\begin{abstract}
This study aims to determine the effect of job design and management information technologi on service quality State Senior High School in Nort Jakarta.The method used ini this research is survey method with path analysis techniques. This study used a population of teachers State Senior High School in Nort Jakarta much as 150 teachers. Sampling techniques in this study is proportional random sampling methode.Based on the results of the study can be summarized as follows: Firstly, there is the effect of job design on service quality; Secondly, there is the effect of management information technology on service quality; Third, there is the effect of job design on management information technology.
\end{abstract}

Keywords: job design, management information technology, service quality.

\section{PENDAHULUAN}

Perkembangan dalam dunia pendidikan telah mengalami peningkatan yang cukup signifikan.Pendidikan telah menjadi bagian dari kebutuhan primer masyarakat yang harus dipenuhi.Pada saat ini hampir tidak ada lagi masyarakat yang tidak mengenal pendidikan, meskipun berbeda dalam jenjang yang mampu ditempuhnya.Pemerintah dalam hal ini juga telah memberikan perhatian yang cukup tinggi terhadap peningkatan mutu pendidikan di Indonesia. Hal tersebut dapat dilihat dari berbagai aspek, diantaranya adalah terbitnya UU Nomor 32 Tahun 2013 tentang Pendidikan Menengah, Peraturan Pemerintah No. 32 Tahun 2013 tentang perubahan terhadap Standar Nasional Pendidikan, dan Peraturan Pemerintah No. 4 Tahun 2014 tentang Penyelenggaraan Pendidikan Tinggi dan Pengelolaan PerguruanTinggi.

Malik Fadjar, sebagaimana dikutip Mujamil Qomar menyarankan sekurangkurangnya ada empat hal yang harus dilihat dalam gerak pendidikan, yaitu pertumbuhan (growth), perubahan (change), pembaruan (development), dan keberlanjutan (sustainability). Fenomena ini akan berkembang secara dinamik sehingga menuntut kepekaan para manajer dalam merespon munculnya gejalagejala tersebut, melalui serangkaian penataan strategi baru yang kondusif dalam memajukan lembaga pendidikan salah satu faktor yang turut mempengaruhi laju perkembangan dalam dunia pendidikan adalah pemanfaatan Teknologi Informasi dan Komunikasi (TIK).

\footnotetext{
* Wirausaha
} 
Dalam menyusun desain pekerjaan pasti akan mempertimbangkan kebutuhan teknologi. Pada era kemajuan teknologi seperti sekarang ini, beberapa pekerjaan sudah dapat diautomatisasi oleh mesin atau program komputer.Berdasarkan hal tersebut, posisi-posisi pekerjaan yang diisi manusia dapat dikurangi atau bahkan dihilangkan. Perubahan desain kerja diharapkan akan menjadikan proses pekerjaan semakin efisien dan efektif.

Perkembangan Teknologi Informasi dan Komunikasi atau yang sering disebut dengan Information Communication Technology (ICT) dewasa ini telah merambah hampir keseluruh lapisan masyarakat di dunia. Pemanfaatan Teknologi Informasi di dunia pendidikan bukan lagi dianggap sebagai sebuah pilihan, namun telah menjelma menjadi kebutuhan mutlak yang harus dimiliki dan dimanfaatkan oleh lembaga pendidikan, jika ingin meningkatkan kualitas penyelenggaraan pendidikannya penerapan teknologi dalam dunia pendidikan tidak hanya ada pada sekolah berkelas internasional, tetapi sampai dengan sekolah yang masih bertaraf lokal sekalipun telah menerapkannya, yang membedakan adalah tingkat pemanfaatan dan cakupan aspek atau layanan yang menggunakan teknologi

Fokus penggunaan teknologi ini tidak saja untuk keperluan administrasi manajemen pendidikan, melainkan sebagai media utama dalam penyelenggaraan kegiatan pembelajaran, riset dan pengembangan, serta pelayanan kepada masyarakat.Oleh karena itu pembicaraan mengenai manajemen sekolah tidak dapat lepas dari pembahasan mengenai teknologi informasi dan peranannya, mutu sebuah sekolah tidak dapat lepas dari mutu layanannya.

Fakta sementara yang ditemukan di lokasi penelitian pada saat assesment awal, khususnya di SMK Negeri yang berada di Wilayah Jakarta Utara.Kepuasan siswa terhadap layanan pendidikan yang dilakukan secara langsung oleh guru, staff pendidikan masih belum menunjukkan hasil yang memuaskan.Hal-hal yang sering muncul dan menjadi keluhan siswa adalah masalah layanan pendidikan yang kurang ramah, kurang cepat, dan kadangkala kurang akurat, akibatnya banyak siswa, guru yang kurang puas merasa mendapatkan layanan yang baik.Audiensi ini biasanya dilakukan setiap semester, dan kadangkala setahun sekali sebagai bagian dari proses monitoring dan evaluasi kinerja guru yang dilakukan sekolah.

Fakta lain adalah adanya data pendidikan yang tidak sinkron antara data yang dimiliki. Di samping itu proses untuk mendapatkan data masih sering kesulitan. Padahal jika semua data tersebut terinput ke dalam sistem informasi berbasis komputer onlineakan sangat membantu. Kesulitan-kesulitan terkait akses data yang akurat tersebut ditemukan ketika dilakukan penyusunan barang akreditasi program studi, terjadi selisih data siswa yang masuk, aktif, ijin, keluar pada tahun tertentu. Akibatnya data menjadi kurang akurat dan menyulitkan proses pengisian akreditasi. Berangkat dari fakta tersebut, nampaklah pentingnya layanan pendidikan yang handal, cepat, akurat, dan responsif.Dengan sistem pendidikan berbasis teknologi informasi memungkinkan terjadinya sistem layanan yang akurat, cepat, bersifat masal, dan mudah dilakukan dari mana saja dan dimana saja selama 
ada jaringan internet.Disinilah urgensi dari pengembangan layanan pendidikan berbasis teknologi informasi.

Menurut bapak Holik Pengawas Sekolah Menengah Kejuruan Negeri di Wilayah Jakarta Utara, kurang optimal layanan akdemik tersebut tidak terlepas dari beban kerja guru yang terlalu banyak, sebenarnya beban tersebut akan terasa lebih ringan apabila dukungan sistem sudah berjalan secara optimal. Namun demikian akan menjadi sangat berat apabila banyak layanan yang masih dilakukan secara manual. Untuk itulah salah satu terobosan yang dilakukan SMK Negeri di Wilayah Jakarta Utara untuk mengurangi beban kerja guru, dengan bantuan teknologi untuk urusan surat menyurat yang dibutuhkan siswa, guru, wali murid dan masyarakat umum. Keterlibatan teknologi informasi dalam dunia pendidikan sudah tidak dianggap sebuah pilihan, tetapi telah menjelma menjadi kebutuhan mutlak yang harus dimiliki dan dimanfaatkan oleh sekolah jika ingin meningkatkan kualitas pendidikannya. Penggunaan teknologi informasi juga sangat bermanfaat bagi proses pembelajaran di sekolah, hal ini merupakan salah satu bentuk kepekaan lembaga dalam mencapai kesuksesan. Terkait dengan kepekaan ini, beberapa pendapat, diantaranya adalah Web dan Pettigrew yang menyatakan bahwa kepekaan lembaga (Organizational Responsiveness) merupakan isu utama yang menentukan kesuksesan dalam usaha. Selain itu, Kuratko et.al dan Liao et al juga menyatakan bahwa kemampuan lembaga dalam menjawab perubahan lingkungan dunia luarnya merupakan faktor utama yang menentukan kinerja lembaga.

Pemanfaatan teknologi informasi pada sekolah telah memberikan kesempatan dan potensi untuk melakukan restrukturisasi sistem pembelajaran yang tidak hanya terbatasi oleh ruang kelas persegi empat.Untuk menggabungkan antara teknologi dengan pendidikan, pertama kali kita harus melakukan pengembangan paradigma berpikir kita bahwa teknologi dapat dikembangkan dalam pendidikan dan menyatu dengan sistem pendidikan. Hal tersebut akan membawa peningkatan perubahan sistem pendidikan, dan penggunaan teknologi dalam pendidikan tersebut sering dipahami dengan penerapan perubahan baru dalam pendidikan menggunakan $e$ learning (Electronic Learning). Istilah lain yang berdekatan dan kadang dianggap sama, adalah distance learning (pembelajaran jarak jauh).

Dalam konteks mutu layanan pendidikan, pemanfaatan teknologi informasi dapat memberikan efisiensi dan efektifitas yang sangat besar, diantaranya adalah penghematan dari segi penggunaan kertas, pengurangan kebutuhan SDM staff, dan percepatan layanan sehingga tidak membutuhkan banyak waktu.Dengan penggunaan layanan pendidikan berbasis online, memungkinkan untuk mengurangi bahkan meninggalkan segala jenis penggunaan kertas (paperless). Semua jenis form dan aplikasi pendidikan dilakukan secara online dan digital.

Dengan demikian proses layanan juga dapat dilakukan secara cepat, akurat, dan dapat dilakukan kapan saja dan dari mana saja selama terdapat akses internet. Otomatisasi program telah memungkinkan layanan dilakukan secara mandiri oleh masing-masing stakeholder. Setidaknya terdapat 8 (delapan) stakeholder yang memiliki keterkaitan erat dengan proses inti maupun aktivitas penunjang dari 
sebuah sekolah. Adapun stakeholder yang dimaksud adalah; siswa, alumni, guru, staff, yayasan, karyawan, industri, komunitas, pemerintah, dan institusi pendidikan lain. Dari kedelapan stakeholder tersebut, yang paling merasakan manfaat sistem layanan pendidikan secara langsung adalah siswa, karyawan, dan guru.Upaya efisiensi dengan Teknologi Informasi mestinya dapat dilakukan secara optimal, yaitu dengan mengoptimalkan penggunaan soft document.

Dengan layanan internet, maka sebuah lembaga pendidikan tidak harus memiliki komputer dengan spesifikasi super besar dan cepat untuk menyimpan semua data atau dokumennya.Dengan sistem website, memungkinan sebuah lembaga yang hanya memiliki komputer dengan spesifikasi sederhana selama dapat digunakan untuk akses internet, dapat menyimpan dokumen yang sangat besar dan relatif aman.SMK Negeri 33 Jakarta Utara saat ini telah memiliki jumlah siswa yang cukup banyak.Jika dilihat dari perbandingan jumlah siswa dengan jumlah staff pendidikan yang ada maka tidak ideal, sehingga pilihan menggunakan layanan pendidikan berbasis teknologi informasi sangat tepat dan mendesak untuk diterapkan secara optimal.

Hasil penelitian Xephon, menyatakan bahwa, teknologi informasi adalah proyek penting yang dilaksanakan, dengan motivasi untuk mengeksploitasi investasi yang telah dikeluarkan, dan memberikan layanan yang lebih baik pada pelanggan.Ingleson, menyatakan bahwa melalui IT System dapat dibangun hubungan komunikasi antara konsumen dan pihak manajemen sekolah.Layanan distribusi informasi dua arah dapat dilakukan dengan cepat, sehingga setiap konsumen berkesempatan menyampaikan evaluasi, aspirasi (kritik saran), yang kemudian membangkitkan presepsi bahwa setiap konsumen dapat bertemu dengan pimpinan sekolah (pihak manajemen) secara langsung, tanpa birokrasi yang rumit dan panjang. Dengan memanfaatkan teknologi informasi pada sistem informasi pendidikan online, maka kualitas layanan yang diterima mahasiswa akan meningkat, terutama dalam hal keakuratan informasi, transfer informasi, efisiensi dan realtime.

Sistem teknologi informasi juga akan menaikkan respon konsumen tinggi. Melalui teknologi informasi (Internet, Handphone), pendistribusian dan penyebaran informasi dapat dilakukan dengan cepat, akurat tanpa batas waktu dan ruang.Daya tarik yang ditawarkan oleh masing-masing sekolah pada umumnya berkaitan dengan kualitas layanan, yang dalam penerapannya berbeda-beda antara satu sekolah dengan sekolah lainnya. Dengan tingginya kualitas layanan, diharapkan akan dapat mempengaruhi respon konsumen.

Menurut Zeithaml (2000:230)mengemukakan bahwa "service quality is the extent of discrepancy between customer's expectations or desires and their perceptions"Mutu Pelayanan adalah kesesuaian antara harapan atau keinginan konsumen dengan persepsi konsumen. Kualitas layanan mempunyai banyak karakteristik yang berbeda sehingga kualitas layanan sulit untuk didefinisikan atau diukur.

Sedangkan menurut Mangold dan Babakus (1991:59-70) adalah "service quality is the outcome of a process in which consumers' expectations for the service are compared 
with their perceptions of the service actually delivered"Kualitas layanan adalah hasil dari proses di mana ekspektasi konsumen membandingkan penggunaan jasa dengan penyampaian jasa yang sesungguhnya.

Menurut Stephen P. Robbins dan Mary Coulter (2014: 539)"job design is the way tasks are combined to form complete jobs". Desain kerja adalah cara mengkombinasikan beberapa tugas-tugas untuk melengkapi suatu pekerjaan. Selanjutnya Gareth R. Jones dan Jennifer M. George (2006:340) mendefinisikan "job design is the process by which managers decide how to divide into specific jobs the tasks that have to be performed to provide customers with goods and services"Desain kerja adalah proses dimana manajer memutuskan bagaimana membagi tugas ke pekerjaan spesifik untuk menyediakan kepada pelanggan dengan barang dan jasa.

Pendapat lain yang dikemukakan oleh Mondy(2014:205), menyatakan bahwa "job design is the process of determining the specific tasks to be performed, the methods used in performing these tasks, and how the job relates to other work in organization"Desain kerja adalah proses penentuan tugas-tugas tertentu untuk melakukan sesuatu, metode yang digunakan dalam melakukan tugas-tugas tersebut dan bagaimana pekerjaan tersebut yang berhubungan dengan pekerjaan yang lain dalam organisasi.

Kemudian menurut Robert.L Mathis and John H. Jackson(2011:116) menerangkan bahwa "job design is organizing tasks, duties, responsibilities, and other elements into a productive unit of work" Desain pekerjaan adalah pengorganisasian tugas-tugas, wewenang dan tanggung jawab kedalam suatu unit pekerjaan yang produktif. Kemudian menurut James L. Gibson dan John M. Ivancevich (2012:13) menerangkan bahwa "job design refers to the process by which managers specify the content, methods, and relationships of jobs to satisfy both organizational and individual requirements"Desain pekerjaan adalah proses penentuan tugas-tugas yang akan dilaksanakan, metode-metode yang digunakan untuk melaksanakan tugas-tugas tersebut, dan bagaimana pekerjaan tersebut berkaitan dengan pekerjaan lainnya di dalam organisasi.

Menurut Robert N. Anthony (2007:4) “management an organization consist of group of people who work together to achieve certain common goals"Manajemen adalah oragnisasi yang terdiri dari sekelompok orang yang bekerjasama untuk mencapai tujuan tertentu. McKeown(2009:143) mendefinisikan "technology that is used to create, store, exchange, and use information in its various forms"Teknologi Informasi merujuk pada seluruh bentuk teknologi yang digunakan untuk menciptakan, menyimpan, mengubah, dan menggunakan informasi dalam segala bentuknya.

Menurut A. Neo, John R (2009:5)“ management is planning, organizing, leading and controlling of human and other resources to achieve organizational goals effectively and efficiently"Manajemen adalah merencanakan, mengatur, memimpin dan mengendalikan sumber daya manusia lainnya untuk mencapai tujuan organisasi secara efektif dan efisien. Teknologi Informasi menurut Haag and Keen (1996:30) bahwa "information Technology is a set of tools that help you work with information and perform tasks related to information processing"Manajemen Teknologi Informasi adalah 
seperangkat alat yang membantu orang bekerja dengan informasi dan melakukan tugas-tugas yang berhubungan dengan pemrosesan informasi.

Menurut Heinz Weihrich dan Harold Koontz (2005:4) "management is the process of designing and maintaining an environment in which individuals, working together in group, efficiently accomplish selected aims" Teori yang lain juga diungkapkan oleh Williams and Sawyer (2003:88) "information technology is a technology that combines computing with high-speed communication lines that carry files, sound, and video"Teknologi Informasi adalah teknologi yang menggabungkan komputer dengan jalur komunikasi kecepatan tinggi yang membawa berkas, suara, dan video.

Martin, Andrew(1999:45) mengemukan pendapat tentangteknologi informasi: "information technology is a technology that is not only on computer technology (hardware and software) that will be used to process and store information, but includes communication technology to transmit or disseminate information".Teknologi Informasi merupakan teknologi yang tidak hanya pada teknologi komputer (perangkat keras dan perangkat lunak) yang akan digunakan untuk memproses dan menyimpan informasi, melainkan mencakup teknologi komunikasi untuk mengirim atau menyebarluaskan informasi.

\section{METODE}

Penelitian ini dilakukan di SMK Negeri di Wilayah Jakarta Utara. Waktu yang digunakan peneliti untuk meneliti selama kurun waktu 3 (tiga) bulan sejak penyusunan proposal penelitian. Metode yang dipakai dalam penelitian ini adalah metode survey dan teknik analisis jalur dengan analisis data secara inferensial.Populasi terjangkau dalam penelitian ini adalah semua guru yang bekerja pada Sekolah Menengah Kejuruan (SMK) Negeri di Wilayah Jakarta Utara, berjumlah 240 orang dengan jumlah sampel sebanyak 150guru.Data yang dikumpulkan dalam penelitian dijaring melalui kuesioner yang berupa skala penilaian (rating scale) dengan sebaran skor antara 1 sampai dengan 5.

Setelah dilakukan analisis deskriptif dilanjutkan dengan uji persyaratan analisis berupa uji normalitas, uji linearitas data dan keberartian regresi, dilakukan uji hipotesis dengan menggunakan teknik analisis jalur (path analysis).

\section{HASIL DAN PEMBAHASAN}

\section{Desain Kerja terhadap Mutu Pelayanan Guru}

Dari hasil pengujiian hipotesis pertama dapat disimpulkan bahwa terdapat pengaruh langsung positif desain kerja terhadap mutu pelayanan guru dengan nilai koefisien korelasi sebesar 0,994 dan nilai koefisien jalur sebesar 0,525.Ini memberikan makna desain kerja berpengaruh langsung terhadap mutu pelayanan guru.

Pola hubungan antara kedua variabel ini dinyatakan oleh persamaan regresi $\dot{X}_{3}$ $=46,816+0,589 X_{1}$. Persamaan ini memberikan informasi bahwa setiap perubahan satu unit desain kerja dapat mengakibatkan terjadinya perubahan mutu pelayanan guru sebesar 0,139 pada konstanta 116,099. Hasil analisis korelasi sederhana desain 
kerja terhadap mutu pelayanan guru sangat tinggi, artinya makin baik desain kerja maka makin tinggi mutu pelayanan guru.Demikian pula sebaliknya makin rendah desain keja maka makin rendah pula mutu pelayanan guru.

Hasil penelitian ini senada dengan pendapat beberapa ahli diantaranya Heskett et al (1997:321)desain pekerjaan berdampak pada mutu pelayanan. "Service quality can be achieved throught work place design, job design, employee selection and development, employee reward and recognition, and tool for serving customer"Mutu layanan dapat dicapai melalui desain tempat kerja, desain pekerjaan, pemilihan karyawan dan pengembangan, imbalan karyawan dan pengakuan, serta alat-alat untuk melayani pelanggan.

Pendapat lain dari Alan C. Filley (1976:345) yang menyatakan "the main advantage of job enlargement programs appear to be increased job satisfication and improved quality"Keuntungan utama dari program enlargement (pemekaran) pekerjaan akan menunjukan peningkatan pada mutu layanan.

\section{Manajemen teknologi informasi terhadap Mutu Pelayanan Guru}

Dari hasil pengujiian hipotesis kedua dapat disimpulkan bahwa terdapat pengaruh langsung positif Manajemen teknologi informasi terhadap Mutu Pelayanan Gurudengan nilai koefisien korelasi sebesar 0,993 dan nilai koefisien jalur sebesar 0,434. Ini memberikan makna manajemen teknologi informasi berpengaruh langsung terhadap mutu pelayanan guru.

Pola hubungan antara kedua variabel ini dinyatakan oleh persamaan regresi $\dot{X}_{3}$ $=120,711+0.101 X_{2}$. Persamaan ini memberikan informasi bahwa setiap perubahan manajemen teknologi informasi dapat mengakibatkan terjadinya perubahan mutu pelayanan guru sebesar 0,101 pada konstanta 120,711.Hasil analisis korelasi sederhana manajemen teknologi informasi terhadap mutu pelayanan guru sangat tinggi, artinya makin baik manajemen teknologi informasi, maka makin tinggi mutu pelayanan guru.Demikian pula sebaliknya makin buruk manajemen teknologi informasi maka makin rendah pula mutu pelayanan guru.

Hasil penelitian ini senada dengan pendapat beberapa ahli diantaranya adalah O'Brien (2007:46) berpendapat bahwa terdapat hubungan antara teknologi informasi terhadap mutu pelayanan. "Information system technology in this relationship focused on significantly improving thr quality of service to customers and suppliers in firm's distribution, marketing, sales, and service activities, more recent project characterize a move toward more innovative uses of information technology" Teknologi sistem informasi dihubungkan dan difokuskan untuk secara signifikan meningkatkan kualitas layanan kepada pelanggan dan penyedia layanan seperti perusahaan distribusi, pemasaran, penjualan dan layanan jasa lainnya. Proyek yang baru memiliki ciri kearah yang lebih inovatif dalam penggunaan teknologi.Zeithaml (2002:22)mendefinisikan "information technology can contribute to service quality in a service based industries" Teknologi dapat berkontribusi terhadap mutu pelayanan dalam layanan informasi berbasis industri.Kemudian dikuatkan oleh Wedemeyer (2007:132) mengatakan bahwa:"Information Technology (IT) based Model The main 
theory that guides this study is the information technology based model. This model highlights the importance of information technology (IT)-based service options among service providers who are using IT to reduce costs and create value-added services for their customers"Informasi teknologi berbasis model teori utama yang memadukan studi adalah model berbasis teknologi informasi. Model ini menyoroti pentingnya teknologi informasi yang menggunakannya, untuk menghemat biaya pengeluaran dan menciptakan nilai tambah layanan untuk pelanggan mereka.

Pendapat lain dikemukakan oleh D. Miller (2008:49)yaitu: "if a company chooses a low cost strategy, a technology information structure is preferred, because it maximizes production and service quality"Jika sebuah perusahaan atau organisasi memilih strategi penghematan biaya produksi, dengan menggunakan informasi teknologi maka akan memaksimalkan produk dan meningkatkan mutu pelayanan

\section{Desain Kerja terhadap Manajemen Teknologi Informasi}

Dari hasil pengujiian hipotesis ketiga dapat disimpulkan bahwa terdapat pengaruh langsung positif desain kerja terhadap manajemen teknologi informasi dengan nilai koefisien korelasi sebesar 0,989 dan nilai koefisien jalur sebesar 0,989.Ini memberikan makna desain kerja berpengaruh langsung terhadap manajemen teknologi informasi.

Pola hubungan antara kedua variabel ini dinyatakan oleh persamaan regresi $\dot{X}_{2}$ $=103,977+0,253 X_{1}$. Persamaan ini memberikan informasi bahwa setiap perubahan desain kerja dapat mengakibatkan terjadinya perubahan manajemen teknologi informasi sebesar 0,253 pada konstanta 103,977. Hasil analisis korelasi sederhana desain kerja terhadap manajemen teknologi informasi sangat tinggi, artinya makin baik desain kerja, maka makin baik manajemen teknologi informasi.Demikian pula sebaliknya makin rendah desain kerja maka makin buruk pula manajemen teknologi informasi. Desain kerja secara langsung berpengaruh positif terhadap teknologi informasi hal tersebut di dukung oleh pernyataan Richard M. Hodgets (1997:400) yaitu: "technology can effect organizational structure; and to the extent that the structure impact on interpersonal relations and organizational climate, it is a job design variable" Teknologi dapat dipengaruhi struktur orgnisasi dan srtuktur berdampak pada hubungan interpersonal dan iklim organisasi yang merupakan varibel desain pekerjaan. Pendapat lain yang dikemukan oleh Gerwin (1997:41) yaitu: "job design is another factor to consider management technology information to the best organizational structure for the situation"Desain kerja merupakan salah satu faktor yang mempengaruhi manajemen Teknologi informasi dalam sebuah organisasi yang baik.

McShine and Von Glinow (2015:391)menuliskan "organizational leader decide how large to grow and which management technology information to use" Seorang pemimpin organisasi atau perusahaan dapat mengetahui bagaimana melakukan perluasan kerja (job enlargement) yang merupakan bagian dari desain pekerjaan dengan menggunakan manajemen teknologi informasi. 


\section{PENUTUP}

Kesimpulan: Berdasarkan hasil perhitungan data penelitian dan hasil analisis data yang telah diuraikan, maka dapat diperoleh beberapa kesimpulan sebagai berikut: 1) Desain kerja berpengaruh langsung positif terhadap mutu pelayanan. Artinya,penerapan desain kerja mengakibatkan peningkatan mutu pelayanan guru Sekolah Menengah Kejuruan (SMK) Negeri di Wilayah Jakarta Utara.2) Manajemen Teknologi Informasiberpengaruh langsung positif terhadap Mutu pelayanan.Artinya,peningkatan manajemen teknologi informasimengakibatkan peningkatan mutu pelayanan guru Sekolah Menengah Kejuruan (SMK) Negeri di Wilayah Jakarta Utara.3) Desain Kerja berpengaruh langsung positif terhadap Manajemen Teknologi Informasi. Artinya,peningkatan desain kerja mengakibatkan peningkatan manajemen teknologi informasi guru Sekolah Menengah Kejuruan (SMK) Negeri di Wilayah Jakarta Utara.

Saran: Berdasarkan hasil penelitian dikemukakan beberapa saran: 1) Bagi Dinas PendidikanDinas Pendidikan wilayah Jakarta Utara selaku pengambil kebijakan perlu memperhatikan berbagai varibel berkenaan dengan upaya peningkatan mutu layanan guru Sekolah Menengah Kejuruan (SMK) Negeri di Wilayah Jakarta Utara. Desain kerja dan manajemen teknologi informasimerupakan variabel yang sangat disarankan untuk diperhatikan dan diterapkan agar guru memberikan layanan yang baik dan sesuai dengan harapan. 2) Bagi Kepala Sekolah :Memberikan timbal balik yang positif dari setiap program serta kebijakan yang dikeluarkan dinas pendidikan, menjalin hubungan yang baik dengan kepala sekolah serta harus selalau aktif dari setiap program yang di keluarkan, memberikan kesempatan warga sekolah ikut berpartisipasi dalam pembangunan sekolah. 3) Bagi para peneliti lain agar menindaklanjuti penelitian ini melalui penelitian-penelitian serupa dengan mengembangkan variabel-variabel bebas dan cakupan wilayah penelitian. Hal ini disebabkan masih banyak faktor yang mempengaruhi desain kerja, manajemen teknologi informasi dan mutu layanan.

\section{DAFTAR RUJUKAN}

Bateman, Management Leading $\mathcal{E}$ Collaboration In a Competitive World, New York, NY: McGraw-Hill education, 2015.

Gibson, James L. and John M. Ivancevich, Organizations Behavior, Structure, Processes, New York: McGraw Hill, 2012.

Jones, Gareth R. dan Jennifer M. George, Contemporary Management, New York: McGraw-Hill, 2006.

Lawrence A. Appley, The American Management Association. Michigan: business review, 2005. 
Mathis, Robert. L and John H. Jackson, Human Resource Management. South Western: Cengage Learning, 2011.

McKeown, Patrick. Information Technology and the Network Economy, London: A Global Text, 2009.

McShine and Von Glinow, Organizational Behavior Emerging Knowledge, Global Reality 7E, Global Edition, New York: McGraw-Hill, 2015.

Miller, D., "Configuration of Strategy and Structure," Cambridge, MA: MIT Press, 2008.

Mondy, R.W \& Mondy, J.B. Human Resources Management, 13 thEd, England: Pearson Education Limited, 2014.

O'Brien, James A. Introduction Information System, published by Mc.Graw Hill Companies, Inc., Avenue of the America, New York, NY, 2007.

Robbins, Stephen P. dan Mary Coulter, Management, United State of America: Pearson Education, 2014.

Robert N, Anthony., Management Control Systems Twelfth Edition, New York, NY: McGraw-Hill Company, 2007.

Sarosa, S. and D. Zowghi, Strategy for adopting information technology for SMEs: Experience in adopting email within an Indonesian furniture company. Electronic Journal of Information Systems Evaluation 6(2): 2003.

Simamora, Henry. Management Sumber Daya Manusia. Edisi Ketiga. STIE Yogyakarta, 2004.

Waddel Devine Jones G., Contemporary Management, New York, NY: McGraw-Hill Australia Pty Limited, 2009.

Wedemeyer, Michael. The ITIL V3Factsheet Benchmark Guide. Elsevier Science Ltd, 2007.

Weihrich, Heinz dan Harold Koontz, Management a Global Perspective, Elevent Edition, New York, NY: McGraw-Hill education. 2005.

Williams and Sawyer, Using Information Technology: A Practical Introduction to Computer and Communications, London: Career Education, 2003.

Zeithaml, VA. Parasuraman, A. and Berry, LL Delivery, Quality service; Balancing Customer Perspections and Expectation, New York: The Free Press, 2002. 